\title{
RIPK3 deficiency or catalytically inactive RIPK1 provides greater benefit than MLKL deficiency in mouse models of inflammation and tissue injury
}

\author{
K Newton ${ }^{\star, 1}$, DL Dugger ${ }^{1}$, A Maltzman ${ }^{1}$, JM Greve ${ }^{2}$, M Hedehus ${ }^{2}$, B Martin-McNulty ${ }^{2}$, RAD Carano ${ }^{2}$, TC Cao ${ }^{2}$, N van Bruggen ${ }^{2}$,

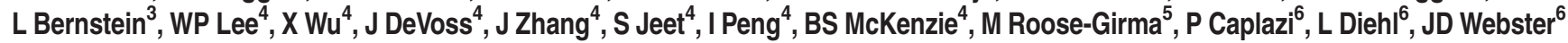 \\ and D Vucic ${ }^{*, 7}$
}

Necroptosis is a caspase-independent form of cell death that is triggered by activation of the receptor interacting serine/threonine kinase 3 (RIPK3) and phosphorylation of its pseudokinase substrate mixed lineage kinase-like (MLKL), which then translocates to membranes and promotes cell lysis. Activation of RIPK3 is regulated by the kinase RIPK1. Here we analyze the contribution of RIPK1, RIPK3, or MLKL to several mouse disease models. Loss of RIPK3 had no effect on lipopolysaccharide-induced sepsis, dextran sodium sulfate-induced colitis, cerulein-induced pancreatitis, hypoxia-induced cerebral edema, or the major cerebral artery occlusion stroke model. However, kidney ischemia-reperfusion injury, myocardial infarction, and systemic inflammation associated with A20 deficiency or high-dose tumor necrosis factor (TNF) were ameliorated by RIPK3 deficiency. Catalytically inactive RIPK1 was also beneficial in the kidney ischemia-reperfusion injury model, the high-dose TNF model, and in $\mathrm{A2O}^{-1-}$ mice. Interestingly, MLKL deficiency offered less protection in the kidney ischemia-reperfusion injury model and no benefit in $\mathrm{A2O}^{-1}$ mice, consistent with necroptosis-independent functions for RIPK1 and RIPK3. Combined loss of RIPK3 (or MLKL) and caspase-8 largely prevented the cytokine storm, hypothermia, and morbidity induced by TNF, suggesting that the triggering event in this model is a combination of apoptosis and necroptosis. Tissue-specific RIPK3 deletion identified intestinal epithelial cells as the major target organ. Together these data emphasize that MLKL deficiency rather than RIPK1 inactivation or RIPK3 deficiency must be examined to implicate a role for necroptosis in disease.

Cell Death and Differentiation (2016) 23, 1565-1576; doi:10.1038/cdd.2016.46; published online 13 May 2016

Necroptosis is considered a pro-inflammatory form of cell death because rupturing of the cell releases intracellular contents that can stimulate innate immune cells. The core necroptosis machinery comprises the receptor interacting

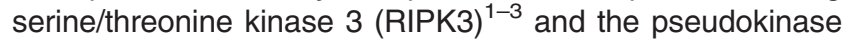
mixed lineage kinase-like (MLKL). ${ }^{4-6}$ RIPK3 can be activated in certain cell types, including mouse macrophages and fibroblasts, by treatment with tumor necrosis factor (TNF) and a pan-caspase inhibitor, although Toll-like receptor 4 (TLR4) agonist lipopolysaccharide (LPS) or TLR3 agonist poly(l:C) can substitute for TNF. ${ }^{1,7-10}$ Autophosphorylated RIPK3 phosphorylates $\mathrm{MLKL}^{4,11}$ and a conformational change in MLKL is thought to drive its oligomerization and translocation to membranes, although precisely how MLKL promotes cell rupture remains contentious. $^{12-17}$

Evidence that necroptosis is pro-inflammatory in vivo stems from genetic studies. For example, skin inflammation in mice lacking RIPK1 can be suppressed by deletion of either RIPK3 or MLKL. ${ }^{18,19}$ RIPK3 or MLKL deficiency also ameliorates liver inflammation and splenomegaly in Sharpin mutant mice. ${ }^{20}$ The contribution of necroptosis to inflammation in human diseases or in many widely used mouse models of disease is less clear. Phosphorylation of MLKL by RIPK3 is considered a marker of necroptosis induction but antibodies recognizing the relevant phosphorylation sites have only been used in a limited number of settings. ${ }^{12,21}$ To date, investigators have largely inferred that necroptosis exacerbates tissue injury because mice lacking RIPK3 or expressing catalytically inactive RIPK1 are less affected in models of pancreatitis, ${ }^{1,3}$ atherosclerosis, ${ }^{22}$ retinal degeneration, ${ }^{23}$ kidney ischemia-reperfusion injury, ${ }^{24}$ Gaucher's disease ${ }^{25}$ myocardial infarction, ${ }^{26,27}$ and systemic inflammatory response (SIRS) syndrome..$^{10,28}$ However, emerging data suggest that RIPK3 and RIPK1 also

\footnotetext{
${ }^{1}$ Department of Physiological Chemistry, Genentech, Inc., 1 DNA Way, South San Francisco, CA 94080, USA; ${ }^{2}$ Department of Biomedical Imaging, Genentech, Inc., 1 DNA Way, South San Francisco, CA 94080, USA; ${ }^{3}$ Department of Biostatistics, Genentech, Inc., 1 DNA Way, South San Francisco, CA 94080, USA; ${ }^{4}$ Department of Translational Immunology, Genentech, Inc., 1 DNA Way, South San Francisco, CA 94080, USA; ${ }^{5}$ Department of Molecular Biology, Genentech, Inc., 1 DNA Way, South San Francisco, CA 94080, USA; ${ }^{6}$ Department of Pathology, Genentech, Inc., 1 DNA Way, South San Francisco, CA 94080, USA and ${ }^{7}$ Department of Early Discovery Biochemistry, Genentech, Inc., 1 DNA Way, South San Francisco, CA 94080, USA

*Corresponding author: K Newton, Department of Physiological Chemistry, Genentech, Inc., 1 DNA Way, South San Francisco, CA 94080, USA. Tel: 650 225 8479; Fax: 650225 6443; E-mail: knewton@gene.com

or D Vucic, Department of Early Discovery Biochemistry, Genentech, Inc., 1 DNA Way, South San Francisco, CA 94080, USA. Tel: 6502258839 ; Fax: 6502256443 ; E-mail: domagoj@gene.com

Abbreviations: RIPK, receptor-interacting protein kinase; MLKL, mixed lineage kinase-like; TNF, tumor necrosis factor; TLR, Toll-like receptor; LPS, lipopolysaccharide; DSS, dextran sodium sulfate; MRA, magnetic resonance angiography; PComAs, posterior communicating arteries; MRI, magnetic resonance imaging; TTC, 2,3,5triphenyltetrazolium chloride; SIRS, systemic inflammatory response syndrome; TNFR1, TNF receptor 1; IECs, intestinal epithelial cells; IAP, inhibitor of apoptosis; MCAO, major cerebral artery occlusion

Received 03.2.16; revised 13.4.16; accepted 13.4.16; Edited by J Silke; published online 13.5.2016
} 


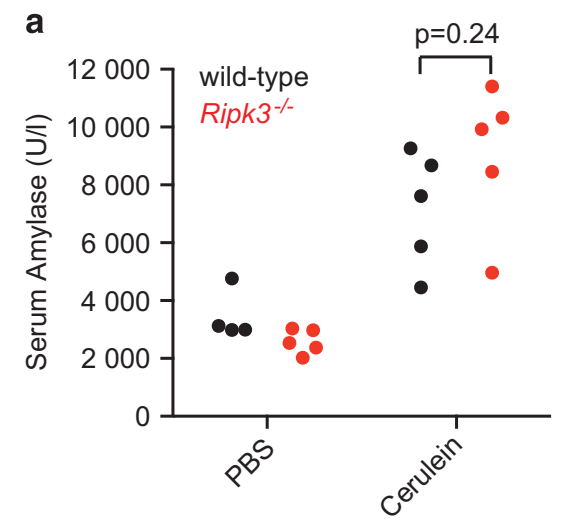

b

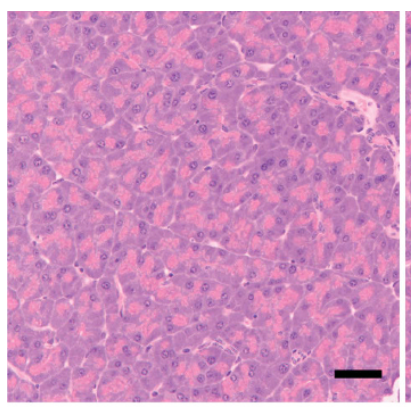

wild-type, cerulein

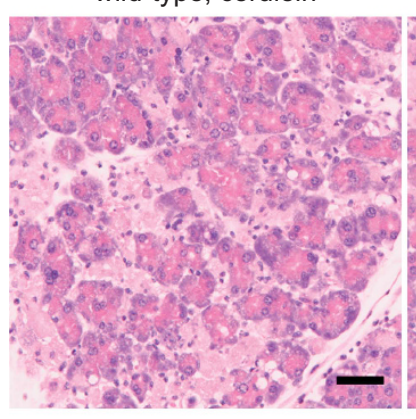

d wild-type, PBS

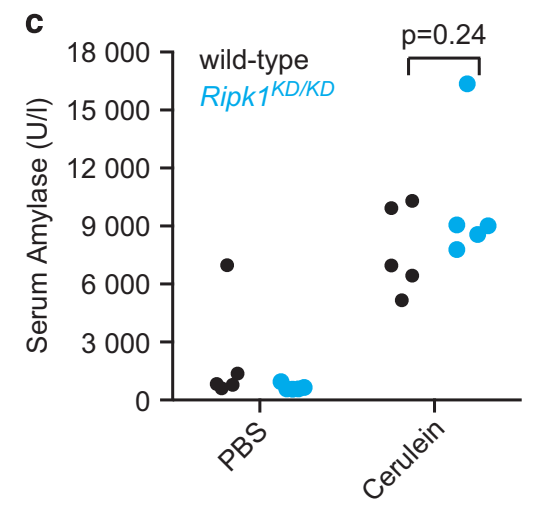

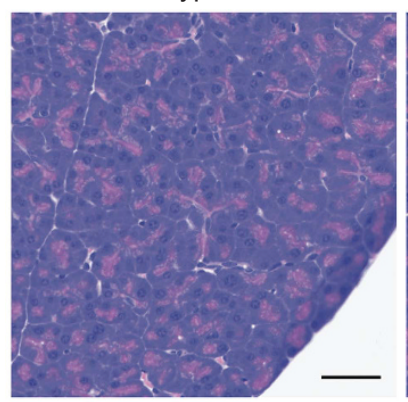

wild-type, cerulein

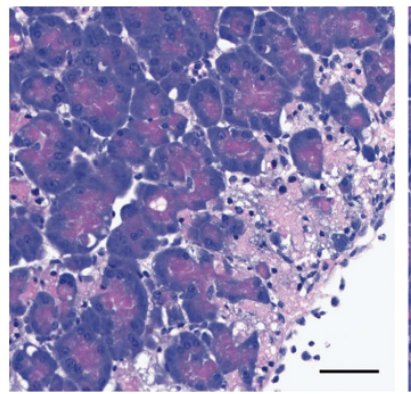

Ripk3\% ${ }^{-/}$PBS

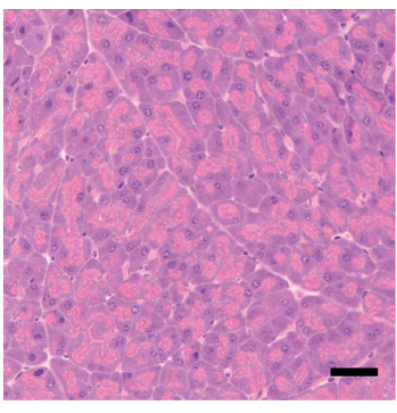

Ripk3\% $^{-/}$, cerulein

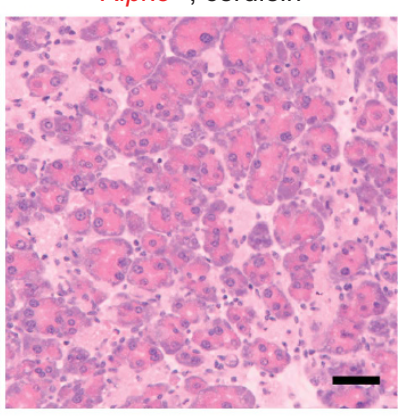

Ripk $1^{K D / K D}$, PBS

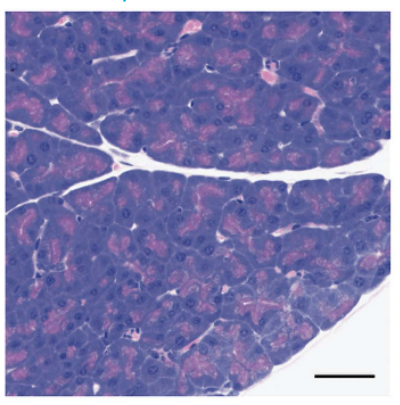

Ripk $1^{K D} / K D$, cerulein

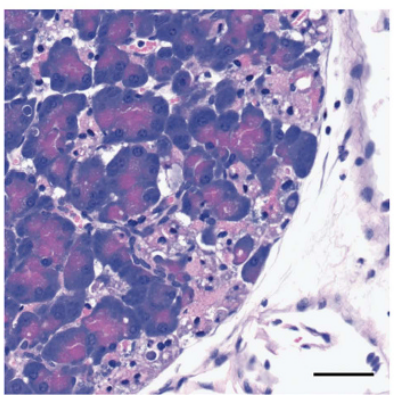

Figure 1 Cerulein-induced pancreatitis was not reduced in Ripk $3^{-/-}$mice or Ripk $1^{K D / K D}$ mice. (a and $\mathbf{b}$ ) Male mice injected intraperitoneally with cerulein hourly for a total of 10 injections. Serum amylase levels (a) and pancreas histology (b) were analyzed at $24 \mathrm{~h}$ after the first injection. (c and d) Female littermates injected with cerulein hourly for a total of seven injections. Serum amylase levels (c) and pancreas histology (d) were analyzed at $1 \mathrm{~h}$ after the last injection. Each symbol in (a) and (c) corresponds to one mouse. $P$-values were determined using the $t$-test. Pancreata in (b) and (d) were stained with hematoxylin and eosin. Scale bars, $50 \mu \mathrm{m}$

have necroptosis-independent functions. ${ }^{29-31}$ In this study, we identify some mouse disease models where RIPK3 loss or catalytically inactive RIPK1 ameliorates disease and then, in a subset of these models, explore whether MLKL deficiency provides a similar degree of protection.

\section{Results}

LPS, cerulein, and dextran sodium sulfate-induced tissue injury and certain brain injuries are not reduced by RIPK3 loss. It has been reported that mice lacking either RIPK3 or MLKL are resistant to cerulein-induced pancreatitis. ${ }^{1,3,9}$ 
a

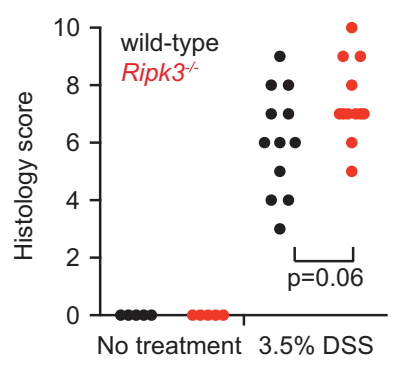

b

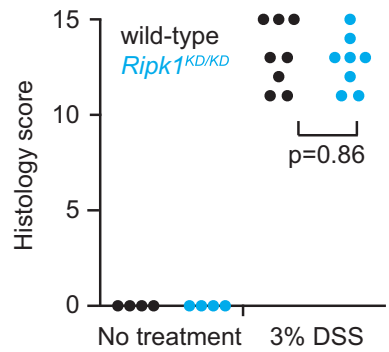

c

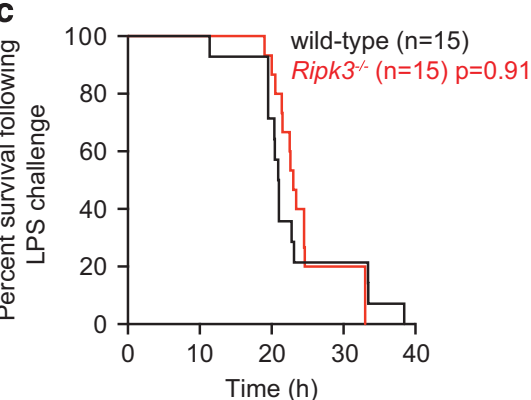

e

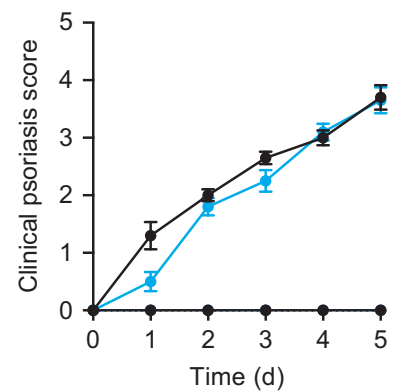

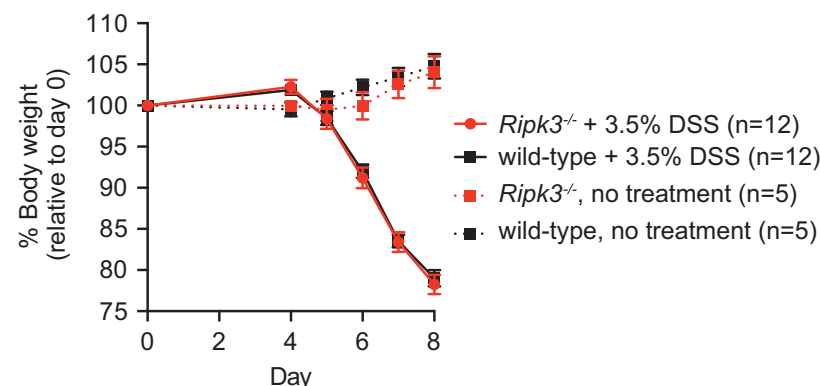
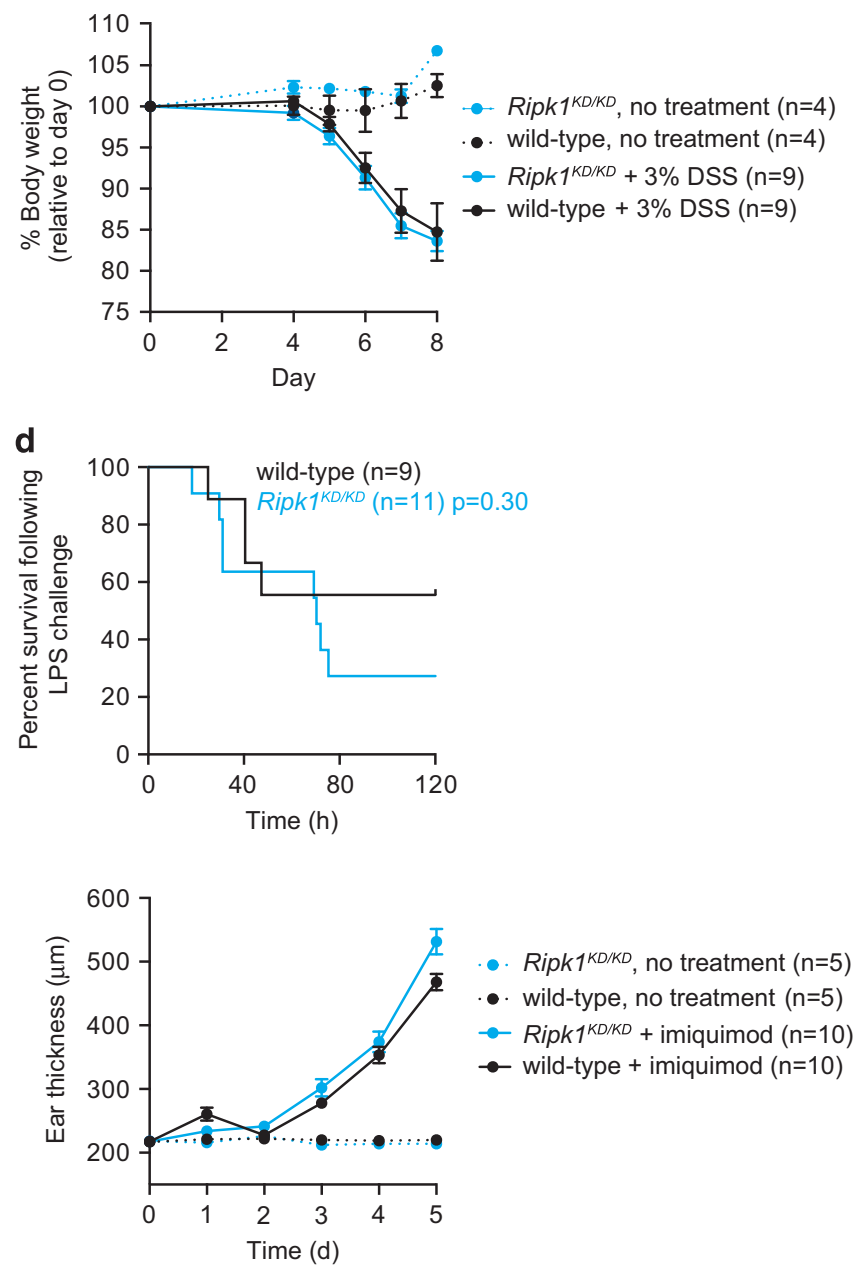

Figure 2 DSS-induced colitis and LPS-induced morbidity were not ameliorated by RIPK3 loss. (a and $\mathbf{b}$ ) Graphs indicate the histology scores (left) or relative body weights (right) of female mice given DSS in their drinking water on days 1-5. Histology score data in (a) and (b) were from different pathologists using slightly different scoring criteria. Error bars, S.E.M. P-values were determined using the t-test. (c and d) Kaplan-Meier survival plots of male mice injected intraperitoneally with $20 \mathrm{mg} / \mathrm{kg}$ body weight LPS (c) and of female littermates injected with $18 \mathrm{mg} / \mathrm{kg}$ body weight LPS (d). P-values were determined using the log-rank test. (e) Mean clinical psoriasis score (left) and ear thickness (right) of female littermates treated with imiquimod. Error bars, S.E.M.

However, in our analyses, wild-type mice, Ripk $1^{K D / K D}$ mice expressing catalytically inactive RIPK1 mutant D138N ${ }^{10}$ and Ripk3 ${ }^{-1-}$ mice ${ }^{32}$ exhibited comparable pancreas morphology and serum amylase levels following challenge with cerulein (Figures $1 a-d$ ). We also saw no significant difference in weight loss or histology scores between wild-type, Ripk $1^{K D / K D}$, or Ripk $3^{-1}$ mice after dosing with dextran sodium sulfate (DSS) to induce colitis
(Figures 2a and b). Another model of tissue injury not impacted by catalytically inactive RIPK1 or RIPK3 deficiency was LPS-induced sepsis (Figures $2 c$ and d). Differences in wild-type morbidity between Figure $2 c$ and Figure $2 d$ are due to different doses of LPS and the use of mice of different sexes; male mice in Figure $2 \mathrm{c}$ received a slightly higher dose of LPS than the female mice in Figure $2 \mathrm{~d}$. Female mice are known to be more resistant than male mice in 
a
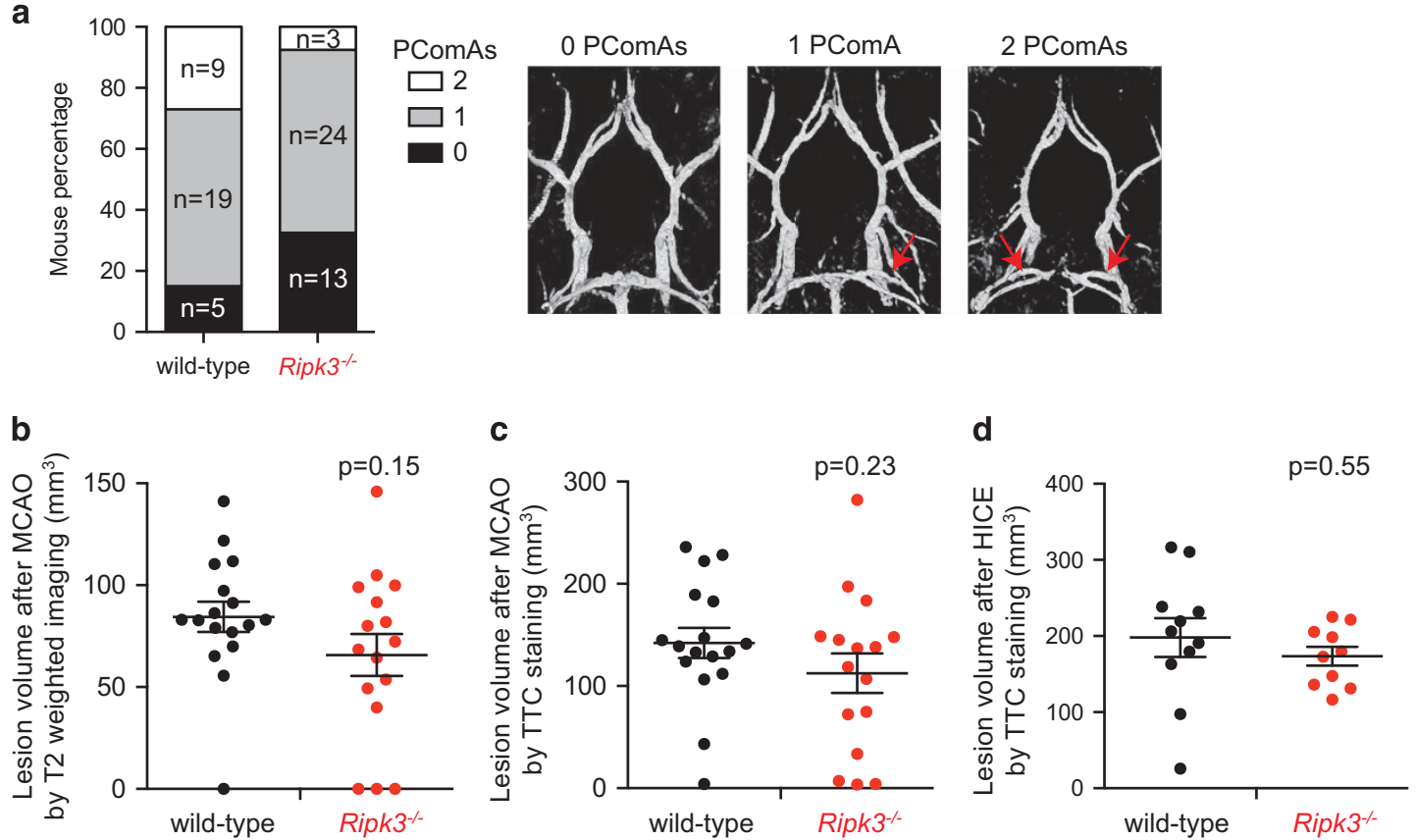

Figure 3 Brain injury following MCAO or hypoxia-induced cerebral edema was not ameliorated by RIPK3 loss. (a) Proportion of male mice having 0 , 1, or 2 posterior communicating arteries (PComAs). Representative brain images are shown with PComAs arrowed. (b and $\mathbf{c}$ ) Brain lesion volumes after MCAO based on T2-weighted imaging (b) or TTC staining (c). (d) Brain lesion volumes after hypoxia-induced edema (HICE) based on TTC staining. Each symbol in (b-d) represents one mouse. Bars indicate the mean volume \pm S.E.M. $P$-values were determined using the $t$-test

experimental models of sepsis. ${ }^{33}$ We also compared imiquimod-induced psoriasis in wild-type and Ripk $1^{K D / K D}$ mice (Figure 2e). A 1.1-fold increase in ear thickness was observed in the Ripk $1^{K D / K D}$ mice after 5 days of treatment, but this did not translate into a significantly worse clinical psoriasis score.

Inhibition of RIPK1 with the small-molecule necrostatin-1 is reported to reduce lesion size in the major cerebral artery occlusion (MCAO) model of stroke, ${ }^{34}$ so we compared wildtype and Ripk ${ }^{-1}$ mice in this model. First, we used magnetic resonance angiography (MRA) to visualize posterior communicating arteries (PComAs) making up the Circle of Willis in the brains of wild-type and Ripk $3^{-/}$mice, because it has been shown in humans that an incomplete Circle of Willis is a risk factor for cerebral infarction. ${ }^{35}$ Mice were identified with 0,1 , or 2 PComAs (Figure 3a), hence we focused only on mice with either 1 or 2 PComAs going forward in order to exclude the effects of an incomplete Circle of Willis. Lesions were induced by occlusion of the major cerebral artery for 50-60 min followed by reperfusion for $24 \mathrm{~h}$ and then their volumes were measured by T2-weighted MRI (magnetic resonance imaging; Figure $3 b$ ) or by 2,3,5-triphenyltetrazolium chloride (TTC) staining (Figure 3c). Lesions in the wild-type and Ripk3 ${ }^{-/}$ brains were not significantly different by either readout. In another study, we examined hypoxia-induced cerebral edema, but again RIPK3 deficiency offered no discernible benefit (Figure 3d).

RIPK3 deficiency ameliorates kidney and heart ischemia-reperfusion injury. In agreement with others, ${ }^{24,26,27}$ we did observe a role for RIPK3 in ischemia-reperfusion injury of the heart and kidney. Ripk $3^{-/}$mice contained significantly smaller heart lesions than wild-type mice at 3 days following ligation of the left coronary artery for 60 min (Figure 4a). To induce kidney injury, both renal pedicles were clamped for $30 \mathrm{~min}$, followed by reperfusion. Ripk $3^{-/}$mice and Ripk $1^{K D / K D}$ mice exhibited improved survival following reperfusion when compared with wild-type mice (Figure 4b). However, MLKL deficiency only extended median survival $\sim 4$ days when compared with wild-type controls (Figure $4 b$ ). These data suggest that RIPK3 can exacerbate kidney injury independently of MLKL and necroptosis. Interestingly, Ripk3 $^{-/}$Casp8 $^{-/-}$mice lacking both RIPK3 and caspase-8 appeared completely protected from renal failure because all mice survived for the duration of the 10-day study, whereas a majority of wild-type mice became moribund within 4 days (Figure 4c). These wild-type mice exhibited extensive renal tubular degeneration and congestion, whereas surviving Ripk3 $^{-/}$Casp8 $^{-/-}$mice had only mild lesions of degeneration with more extensive regeneration (Figure $4 d$ ). We could not determine the effects of caspase- 8 deficiency in isolation because Casp $^{-1-}$ mice die during embryogenesis. ${ }^{36}$

Catalytically inactive RIPK1 or RIPK3 deficiency, but not MLKL deficiency, ameliorates inflammation in A20-deficient mice. Mice lacking the pro-survival protein A20 (also called TNFAIP3) exhibit systemic inflammation and die soon after birth. ${ }^{37}$ Recently, RIPK3 deficiency was reported to delay the death of $A 2 \mathrm{O}^{-/}$mice and it was suggested that A20 limits RIPK3-dependent necroptosis. ${ }^{38}$ We explored this possibility further by seeing if catalytically inactive RIPK1 or MLKL deficiency also delayed lethality in A20-deficient mice. $A 20^{-1-}$ mice were generated through deletion of exon 2 encoding the initiator methionine 
a

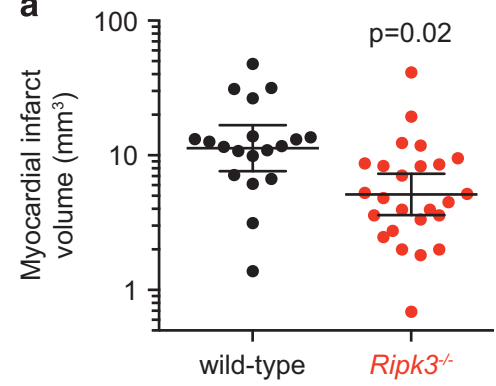

b

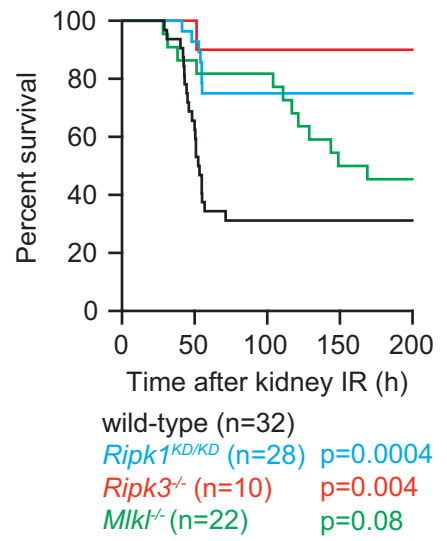

C

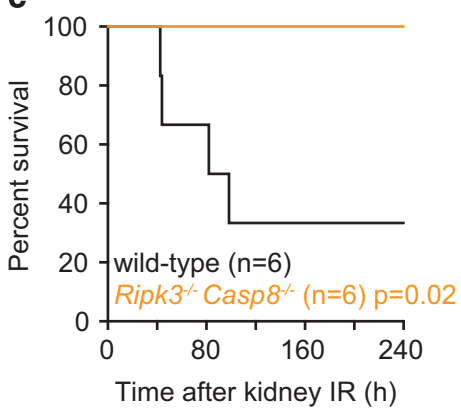

d

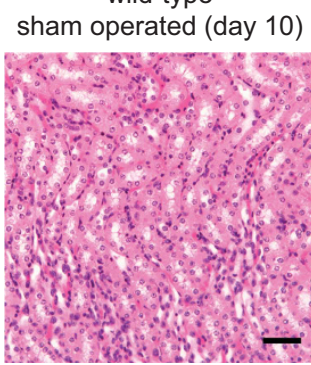

wild-type IR injury (day 3 )

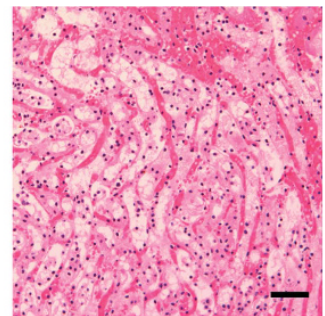

Ripk3\% Casp8\% IR injury (day 10)

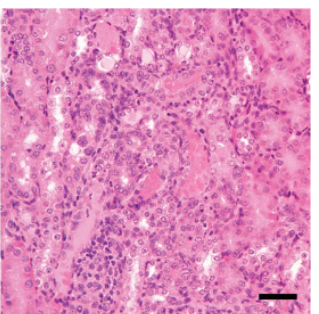

Figure 4 RIPK3 deficiency reduced infarct volume following heart ischemia-reperfusion injury and improved survival following kidney ischemia-reperfusion injury. (a) Heart infarct volumes after ischemia-reperfusion based on TTC imaging. Each symbol represents one male mouse (wild-type, $\left.n=19 ; R i p k 3^{-1}, n=25\right)$. Bars indicate the geometric mean \pm the $95 \%$ confidence interval. $P$-value was determined using the $t$-test. (b and $\mathbf{c}$ ) Kaplan-Meier survival plots of male mice after kidney ischemia-reperfusion (IR). Wildtype mice were $\mathrm{MlK}^{-/}$or Ripk ${ }^{K D / K D}$ littermates. A complete listing of log-rank test $P$-values is provided in Supplementary Table S1. Results from three independent experiments were pooled. (d) Representative kidney sections stained with hematoxylin and eosin. Scale bars, $50 \mu \mathrm{m}$

(Figure 5a), and consistent with the findings of Lee et al., ${ }^{37}$ exhibited severe runting and tissue inflammation with a median survival of 5 weeks (Figure $5 b$ ). Interestingly, either catalytically inactive RIPK1 or RIPK3 deficiency ameliorated the effects of A20 loss, with the median survival of $A 20^{-1-}$ Ripk $3^{-/-}$mice and $A 20^{-1-}$ Ripk $1^{K D / K D}$ mice being 31 and 25 weeks, respectively (Figure $5 \mathrm{~b}$ ). In comparison, median survival of $A 2 \mathrm{O}^{-1-} \mathrm{Mlk}^{-1-}$ mice was only 4 weeks. Histological analysis of 1 -week-old mice revealed that $\mathrm{A2O}^{-/-}, \mathrm{A} 2 \mathrm{O}^{-/-}$ Ripk $1^{K D / K D}$, and $A 20^{-/} \mathrm{MlkF}^{--}$mice all had foci of neutrophilic inflammation in the liver, whereas $A 20^{-1-}$ Ripk3 $^{-/}$mice did not (Figure 5c). RIPK3 deficiency also ameliorated dermatitis and/or panniculitis affecting the skin of A20 ${ }^{-1}$ mice (Figure $5 \mathrm{~d}$ ). Collectively, these data indicate that MLKL-dependent necroptosis does not contribute significantly to the lethality of $A 2 \mathrm{O}^{-1-}$ mice, whereas there is a clear contribution from ill-defined RIPK3-dependent signals. We examined multiple cytokines and chemokines in the sera of 3- to 4-week-old mice, and only RANTES/CCL5 was both elevated in the $A 2 O^{-1-}$ mice and significantly reduced by RIPK3 deficiency (Figure $5 \mathrm{e}$ and Supplementary Figure S1).

Combined loss of MLKL (or RIPK3) and caspase-8 provides significant protection in a model of SIRS. Catalytically inactive RIPK1 or RIPK3 deficiency in mice has been shown to ameliorate hypothermia and morbidity induced by a high dose of TNF, ${ }^{10,28}$ which is considered in the literature to be a model for SIRS. In contrast to Ripk ${ }^{-1-}$ mice, $\mathrm{MlkF}^{-1}$ mice resembled wild-type mice in their sensitivity to hypothermia induced by $300 \mu \mathrm{g}$ TNF per $\mathrm{kg}$ body weight (Figure 6a). However, when mice were dosed with $500 \mu \mathrm{g}$ TNF per kg body weight, which induced more severe hypothermia in wild-type mice (compare $y$ axes in Figures $6 a$ and b), differences between Ripk3 ${ }^{-/}$mice and $\mathrm{MlkI}^{-/}$mice were less apparent (Figures $6 \mathrm{~b}$ and $\mathrm{c}$ and Supplementary Figure S2). Similar to Ripk $3^{-1-}$ mice, the mean body temperature of $\mathrm{MlkF}^{--}$mice was significantly higher than that of wild-type mice at 6, 8, and $10 \mathrm{~h}$ after dosing with $500 \mu \mathrm{g}$ TNF per kg body weight (Figure 6b). Strikingly, $\mathrm{MlkI}^{-1} \mathrm{Casp}^{-/-}$mice lacking both MLKL and caspase-8 appeared completely unresponsive to TNF, with little evidence of hypothermia and greatly reduced serum cytokines and chemokines (Figures $6 \mathrm{~b}$ and $\mathrm{c}$ and Supplementary Figure S2). Ripk3 ${ }^{-/}$Casp $^{-/-}$mice also exhibited little hypothermia in response to TNF (Figure 6d). Collectively, these data suggest that TNF-induced hypothermia and serum cytokines/chemokines are a consequence of caspase-8-dependent apoptosis and MLKL-dependent necroptosis. While we were unable to determine the effects of caspase-8 deficiency alone, heterozygous $\mathrm{Casp}^{+/-}$mice were as resistant as $\operatorname{Ripk} 1^{K D / K D}$ mice to hypothermia induced 
by $500 \mu \mathrm{g}$ TNF per kg body weight (Figure 6e). This result implies that TNF-induced apoptosis is exquisitely sensitive to Casp8 gene dosage.
To assess the cell type(s) in which RIPK3 contributes to TNF-induced toxicity, we employed Ripk $3^{f / f l}$ mice bearing conditional alleles of Ripk3 with exons 2 and 3 flanked by loxP
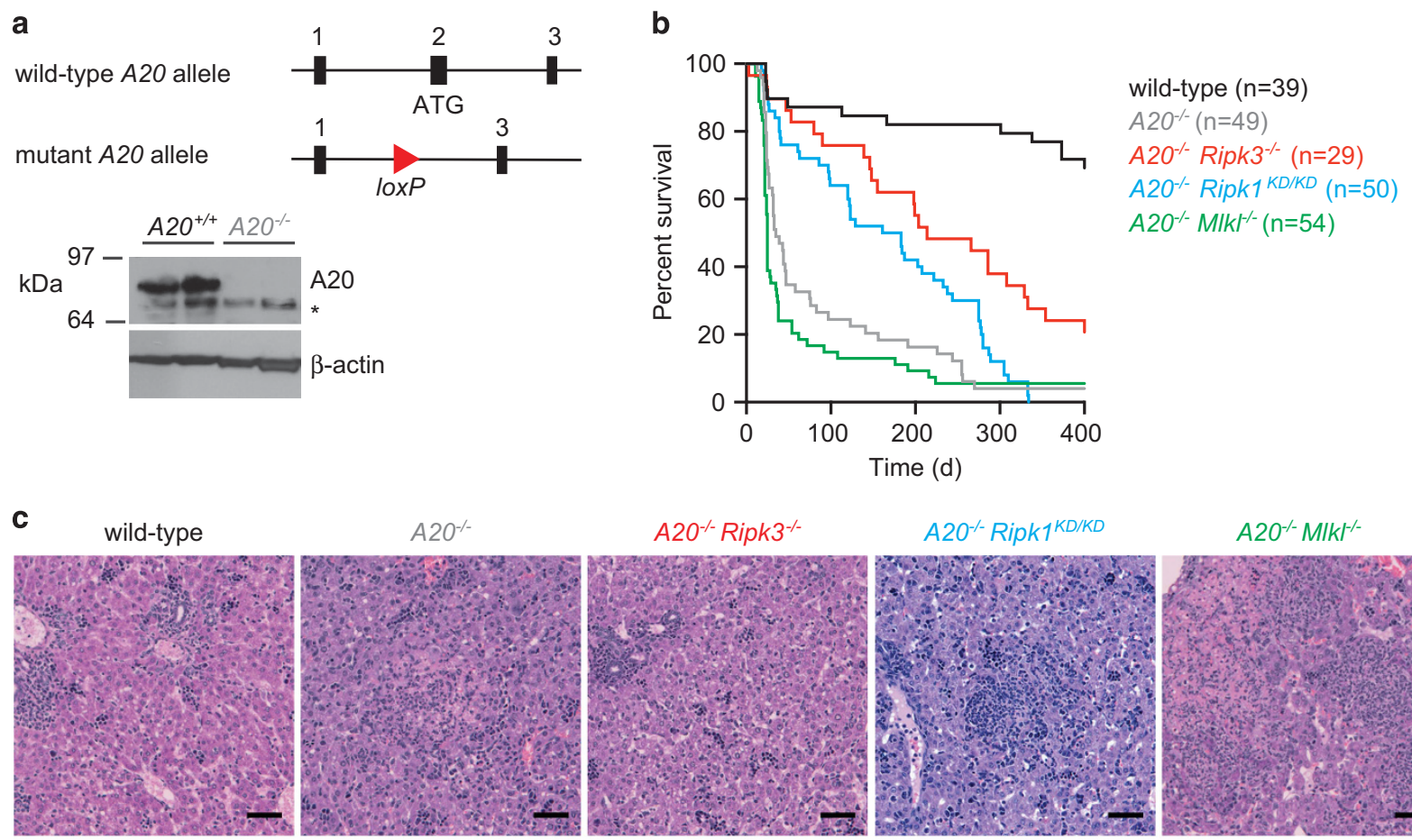

A20-/ Ripk1 KD/KD

A20 ${ }^{-/-} \mathrm{MlkH}^{-/-}$
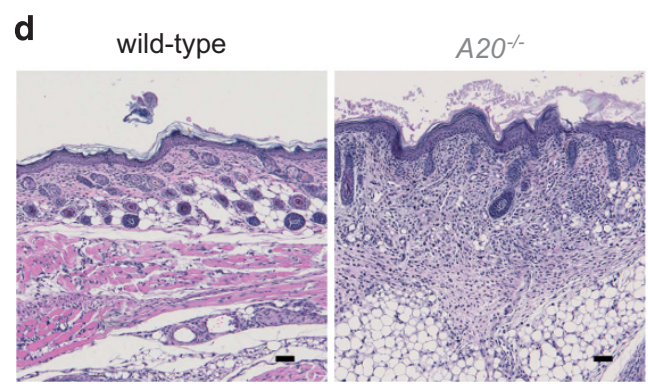

A20\% Ripk3\%
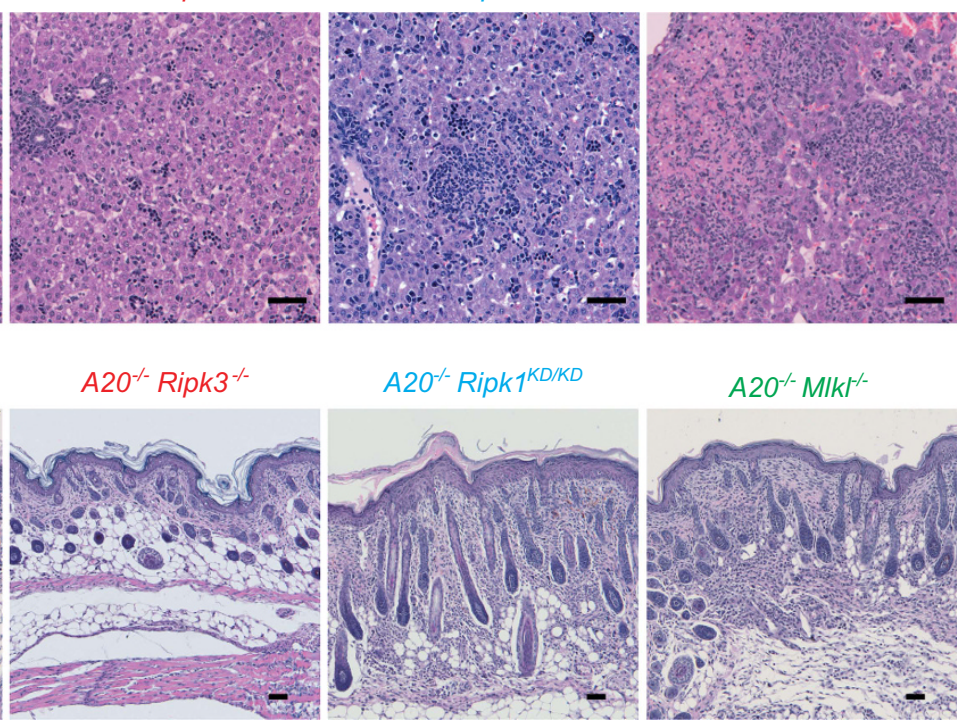

A20-/ Ripk1 1KD/KD

A20-/- $\mathrm{Mlkl}^{-/-}$

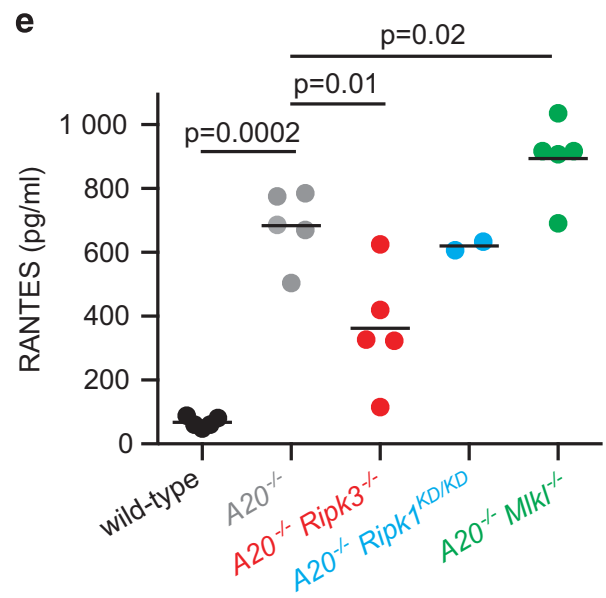

Figure 5 RIPK3 deficiency or catalytically inactive RIPK1 enhanced survival of $\mathrm{A2O}^{-/-}$mice. (a) Diagram of the exons (black boxes) deleted in $\mathrm{A2O}^{-/-}$mice. Lower panels are western blots of bone marrow-derived macrophages. An asterisk indicates a nonspecific band. (b) Kaplan-Meier survival plots. $P$-values determined using the log-rank test are provided in Supplementary Table S2. (c and d) Hematoxylin and eosin-stained liver (c) or skin (d) sections of mice aged 1 week. Scale bars, $50 \mu$ m. Similar results were obtained for 3-4 mice of each genotype. (e) RANTES in the serum of 3- to 4-week-old mice. Each symbol represents one mouse. Bars indicate the mean. $P$-values were determined using the $t$-test. Wild-type mice were $A 20^{-1-}$ littermates 

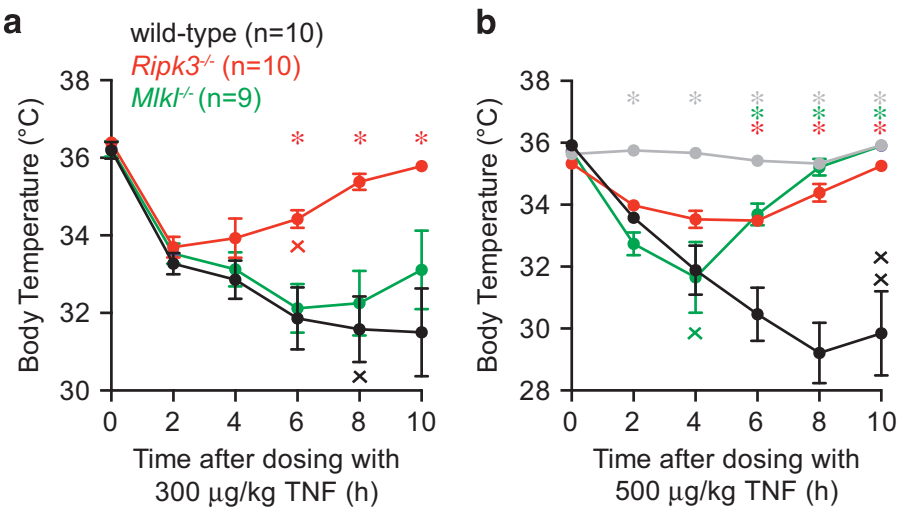

wild-type $(n=9)$

Ripk3- $(\mathrm{n}=9)$

MIkH ${ }^{-}(n=9)$

MIk ${ }^{\kappa} \operatorname{Casp}^{-\%}(\mathrm{n}=6)$

C Serum cytokines/chemokines at $4 \mathrm{~h}$ after dosing with $500 \mu \mathrm{g} / \mathrm{kg}$ TNF
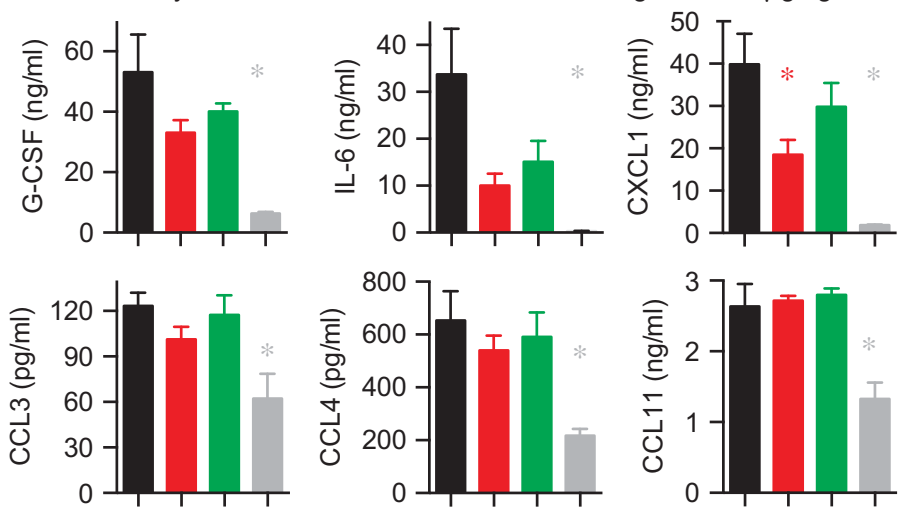

wild-type $(n=5)$

Ripk3 $\%(n=5)$

MIkH $(\mathrm{n}=5)$

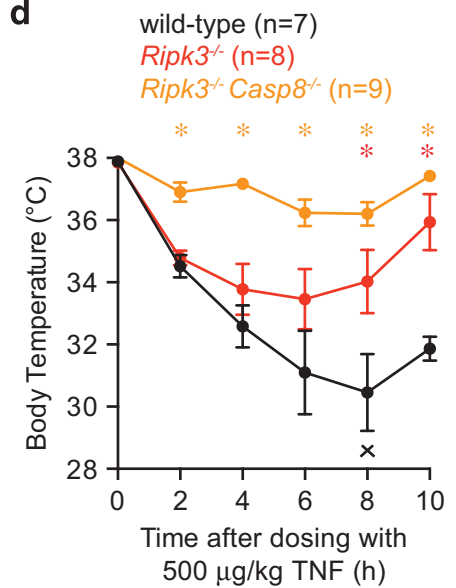
e
- $\operatorname{Casp}^{+/+}(\mathrm{n}=9)$
$\rightarrow \operatorname{Casp}^{+/-}(\mathrm{n}=10)$
$\rightarrow \operatorname{Ripk}^{+/+}(\mathrm{n}=9)$
$\rightarrow$ Ripk $1^{K D / K D}(\mathrm{n}=9)$

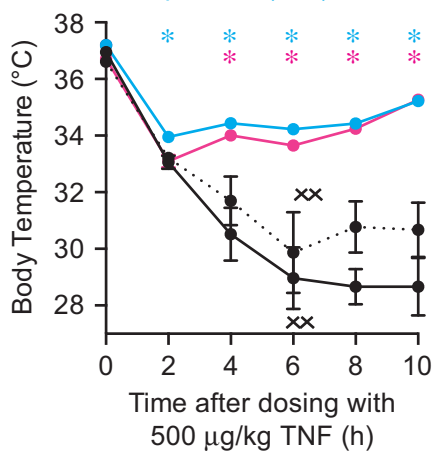

Figure 6 Loss of MLKL (or RIPK3) and caspase-8 provided significant protection against TNF-induced SIRS. Mice were injected with $300 \mu \mathrm{g} / \mathrm{kg}$ body weight (a) or $500 \mu \mathrm{g} / \mathrm{kg}$ body weight ( $\mathbf{b}-\mathbf{e})$ of murine TNF. Body temperatures $(\mathbf{a}, \mathbf{b}, \mathbf{d}$, and $\mathbf{e})$ or serum cytokines (c) are plotted. Data represent the mean \pm S.E.M. In panels $\mathbf{a}, \mathbf{b}, \mathbf{d}$, and $\mathbf{e}$, an $\mathbf{x}$ indicates when a mouse became moribund and had to be killed. Asterisks indicate $P<0.05$ when compared with wild-type by the $t$-test. Wild-type mice were either littermates or they shared grandparents with mice of a comparison genotype

sites (Figure 7a). Expression of TNF receptor 1 (TNFR1) by intestinal epithelial cells (IECs) was reported to be essential for TNF-induced toxicity. ${ }^{39}$ Therefore, we used a villin.cre transgene to delete Ripk3 from IECs. We confirmed reduced RIPK3 expression in Ripk3 ${ }^{t / f t}$ villin.cre IECs by immunohistochemical staining (Figure $7 \mathrm{~b}$ ). In the small intestine, Ripk $3^{f / f t}$ villin.cre IECs stained far less than wildtype IECs and showed comparable staining to IECs in Ripk $3^{-/}$mice. However, clusters of IECs in the small and large intestine of Ripk $3^{f / f l}$ villin.cre mice remained positive for RIPK3, suggesting incomplete Ripk3 gene deletion. Weak labeling of lymphocytes and endothelial cells was observed in both wild-type and Ripk $3^{f / f l}$ villin.cre intestine, but not in Ripk $3^{--}$intestine, consistent with gene deletion mediated by the villin.cre transgene being largely restricted to IECs. Despite evidence of incomplete Ripk3 gene deletion in the intestine, Ripk $3^{t / f t}$ villin.cre mice were as resistant as systemic Ripk3 $3^{-/}$mice to the effects of TNF (Figures 7c 


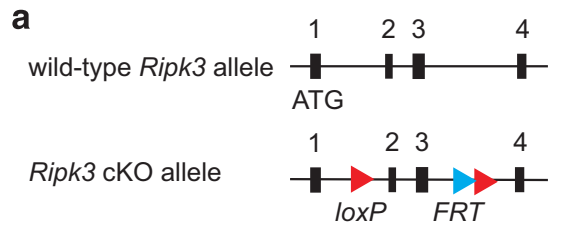

b
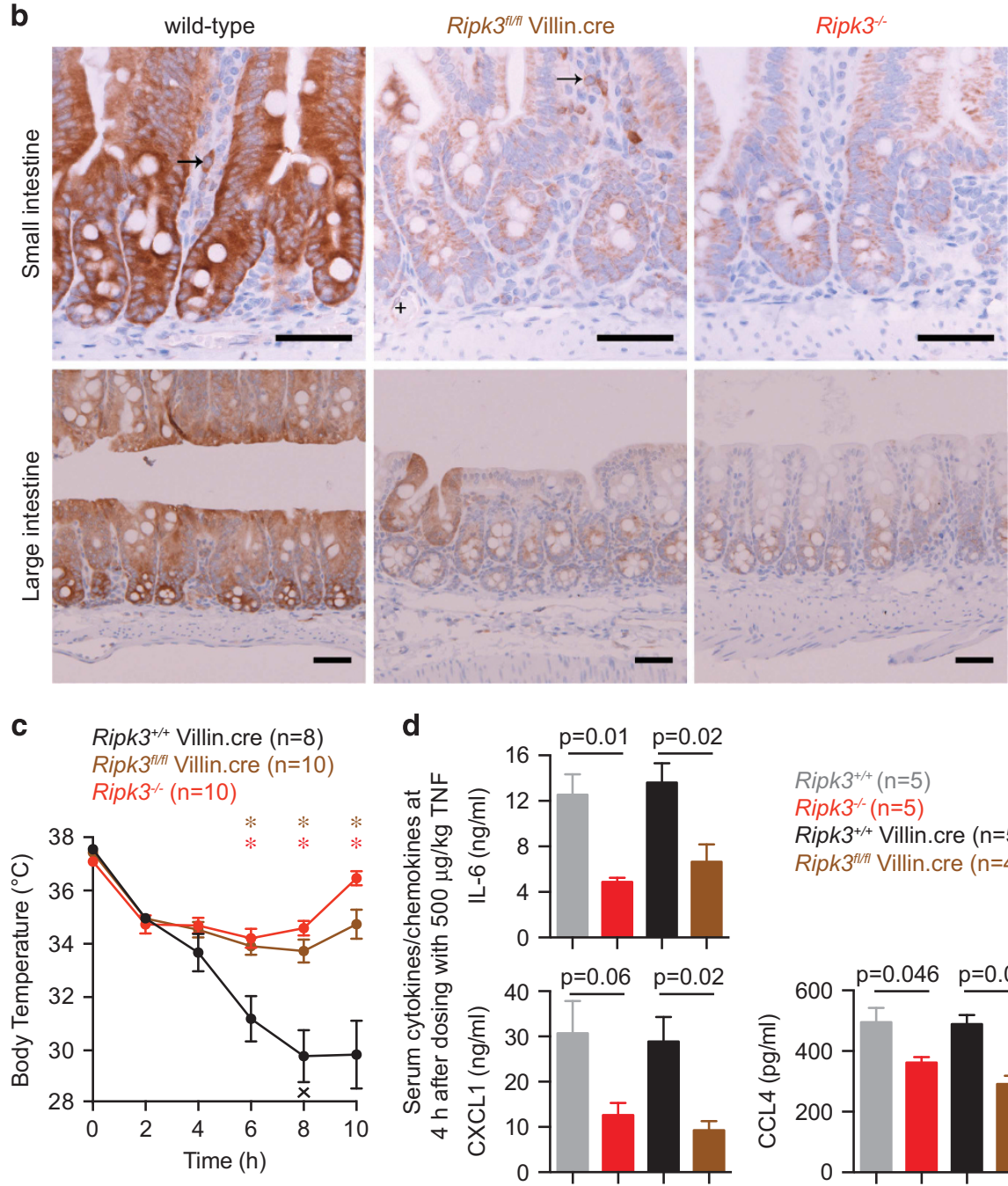

Ripk $3^{+/+}(\mathrm{n}=5)$

$\operatorname{Ripk}^{-\%}(\mathrm{n}=5)$

Ripk $3^{+/+}$Villin.cre $(\mathrm{n}=5)$

Ripk3 $3^{f / f l}$ Villin.cre $(\mathrm{n}=4)$

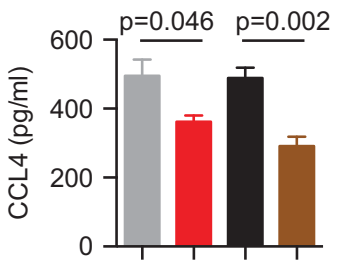

Figure 7 RIPK3 expressed by intestinal epithelial cells mediates TNF-induced toxicity. (a) Diagram of the exons (black boxes) flanked by loxP sites in Ripk3 $3^{t / f t}$ mice. (b) Immunohistochemical staining for RIPK3 (brown). Scale bars, $50 \mu \mathrm{m}$. Arrows indicate RIPK3 ${ }^{+}$immune cells. + indicates a labeled blood vessel. (c) Mean body temperatures of mice given $500 \mu \mathrm{g} / \mathrm{kg}$ body weight murine TNF. Error bars, S.E.M. Asterisks indicate $P<0.05$ when compared with villin.cre controls by the $t$-test. (d) Mean serum cytokines and chemokines at $4 \mathrm{~h}$ after dosing with $500 \mu \mathrm{g} / \mathrm{kg}$ body weight murine TNF. Control mice were littermates of Ripk $3^{-/-}$mice or Ripk $3^{t / f / 1}$ villin.cre mice. Error bars, S.E.M. P-values were determined using the $t$-test

and $d$ and Supplementary Figure S3). These data indicate that RIPK3 expression in IECs is also critical for TNF-induced toxicity.

\section{Discussion}

RIPK3 has been shown to promote apoptosis rather than necroptosis in certain contexts. For example, small-molecule inhibitors of RIPK3 promote caspase-8-dependent apoptosis, ${ }^{40}$ as does catalytically inactive RIPK3 mutant D161N. ${ }^{10}$ Catalytically inactive RIPK3 mutant K51A does not induce apoptosis like RIPK3 mutant D161N so it is thought that a conformational change in RIPK3 promotes apoptosis rather than inhibition of its enzymatic activity. ${ }^{40}$ This pro-apoptotic conformation of RIPK3 may also be relevant in more physiological settings because it has been shown that LPS triggers RIPK3- and caspase-8-dependent apoptosis in macrophages lacking the inhibitor of apoptosis (IAP) proteins, CIAP1, cIAP2, and XIAP. ${ }^{30}$ Collectively, these observations question whether the resistance of Ripk $3^{-/}$mice in various disease models is sufficient to conclude that necroptosis increases disease severity. In a similar vein, RIPK1 enzymatic 
activity, while necessary for death receptor-induced necroptosis, ${ }^{2,3,10,41-44}$ also promotes apoptosis in certain contexts. For example, skin inflammation in Sharpin mutant mice is due to TNFR1-induced keratinocyte apoptosis that requires RIPK1 enzymatic activity. ${ }^{20,44,45}$ The kinase activity of RIPK1 also mediates apoptosis induced by the bacterium Yersinia pestis ${ }^{46,47}$ or by TNF in combination with an IAP antagonist or a TAK1 inhibitor. ${ }^{43,48,49}$

Our finding that MLKL loss was not as effective as RIPK3 loss or catalytically inactive RIPK1 at ameliorating kidney ischemia-reperfusion injury (Figure 4), systemic inflammation in $\mathrm{A}_{2} \mathrm{O}^{-/-}$mice (Figure 5), or TNF-induced toxicity at certain doses of TNF (Figure 6a) supports the notion that RIPK1 and RIPK3 regulate more than just MLKL-dependent necroptosis. Whether RIPK1 and RIPK3 are simply promoting caspase-8dependent apoptosis as well as MLKL-dependent necroptosis in these models is less clear. It is also possible that RIPK3 has a more complex role in promoting tissue injury and inflammation beyond its ability to kill cells. This idea stems from the observation that lymphadenopathy associated with impaired apoptosis induction by the death receptor Fas is more severe in $\mathrm{MlkF}^{--} \mathrm{Casp}^{-/-}$mice than in Ripk3 ${ }^{-/} \mathrm{Casp}^{-1}$ mice (Andreas Strasser, Silvia Alvarez-Diaz and Douglas Green, personal communication). Necroptosis and caspase-8dependent apoptosis are disabled in both strains of mice, so it may be that RIPK3 loss has the added effect of suppressing the production of pro-inflammatory cytokines and chemokines. We looked for such an effect in the $A 20^{-1}$ mouse model, which has elevated levels of many serum cytokines and chemokines, but with the exception of RANTES, most were not diminished by RIPK3 loss (Figure 5e and Supplementary Figure S1).

How might A20 loss engage non-necroptotic RIPK3dependent signaling? It has been proposed that the deubiquitylating activity of $\mathrm{A} 20$ removes ubiquitin that is conjugated to Lys5 in RIPK3 and this prevents interactions between RIPK3 and RIPK1 that promote necroptosis. ${ }^{38}$ However, mice engineered to express catalytically inactive A20 without deubiquitylating activity do not develop the multi-organ inflammation that occurs in mice lacking A20. ${ }^{50-52}$ These genetic data argue that a scaffold function of A20 may be more critical for limiting multi-organ inflammation. Others have proposed that A20 promotes cell survival by binding to linear ubiquitin chains in various signaling complexes (including that nucleated by TNFR1), which then prevents their removal by the deubiquitylating enzyme CYLD. ${ }^{53}$ Preservation of these signaling complexes by A20 might limit RIPK3 engagement. The role of the kinase activity of RIPK1 in mediating morbidity in $\mathrm{A}_{2 \mathrm{O}^{-/}}$mice remains enigmatic; catalytically inactive RIPK1 delayed disease progression (Figure $5 \mathrm{~b}$ ), but it differed from RIPK3 deficiency by not reducing inflammation in the $\mathrm{A} 2 \mathrm{O}^{-1-}$ liver or skin (Figures $5 \mathrm{c}$ and d). A comparison of RIPK3 loss and inactivation of RIPK1 in mice lacking A20 in specific cell types may provide further insights.

Mice with RIPK3 loss restricted to most IECs were as resistant as Ripk $3^{-1}$ mice to TNF-induced hypothermia (Figure 7c), which fits well with TNF engaging TNFR1 on IECs to mediate its toxic effects. ${ }^{39}$ Future studies will need to address where RIPK3 exerts its effects in the kidney and heart ischemia-reperfusion injury models. It is unclear if RIPK3 acts directly in the renal tubular cells and myocardiocytes, or if RIPK3 might also have a role in other cell types such as the vascular endothelium. We did not test whether the kinase activity of RIPK1 contributes to heart ischemia-reperfusion injury, but that is the expectation because inhibition of RIPK1 with the small-molecule necrostatin-1 is reported to be protective in both mice and pigs. ${ }^{54,55}$ Future studies that determine the effect of MLKL deficiency in heart ischemiareperfusion injury should indicate whether necroptosis contributes to this pathology.

Our finding that RIPK3-deficient mice are not protected in the MCAO model of stroke (Figures $3 b$ and $c$ ) is interesting given that inhibition of RIPK1 with necrostatin-1 is reported to be protective in this model. ${ }^{34}$ The differential sensitivity of the MCAO model to RIPK1 inhibition and RIPK3 deficiency is reminiscent of studies with Sharpin mutant mice, where RIPK1 inhibition completely prevents severe skin disease, ${ }^{44}$ but loss of RIPK3 provides only a modest delay in disease onset. ${ }^{20,45}$ RIPK1-dependent apoptosis rather than necroptosis appears to drive pathology in Sharpin mutant mice, and this may also be the case in the MCAO model of stroke.

In contrast to previous reports, ${ }^{1,3}$ we did not find that RIPK3 deficiency ameliorated cerulein-induced pancreatitis (Figures 1a and b). Zhang and colleagues obtained their Ripk $^{-/-}$mice from our facility so we can only speculate that differences in colony microflora between our two institutions might contribute to the discrepancy between our results. Another study reported that inhibiting RIPK1 with necrostatin-1 did not ameliorate cerulein-induced pancreatitis, ${ }^{56}$ which is consistent with our finding that Ripk $1^{K D / K D}$ mice are as sensitive as wild-type mice (Figures $1 \mathrm{c}$ and d). In DSSinduced colitis, Ripk ${ }^{-/}$mice are reported to be more susceptible than their wild-type counterparts, ${ }^{57}$ whereas necrostatin-1 is reported to protect mice. ${ }^{58}$ We did not observe statistically significant differences in the weight loss or histology scores of wild-type and Ripk ${ }^{-1-}$ mice that were given DSS in their drinking water for 5 days (Figure 2a). However, Moriwaki et al. ${ }^{57}$ provided mice with DSS for 8 days and this extended stress might have amplified subtle differences between the wild-type and Ripk $3^{-1-}$ mice. Our Ripk $1^{K D / K D}$ mice also showed normal sensitivity to DSSinduced colitis (Figure 2b), so we wonder if the results of Liu et al. ${ }^{58}$ with necrostatin-1 might reflect inhibition of the enzyme indoleamine 2,3-dioxygenase rather than RIPK1. ${ }^{59}$

\footnotetext{
Materials and Methods

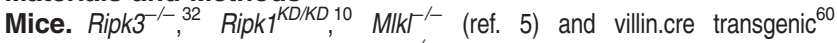
mice were described previously. Ripk $3^{-1-}$ mice used in Figures $4 \mathrm{~b}$ and e, and Figures 5, 6, and 7 lacked the neomycin selection cassette as described. ${ }^{10}$ All Ripk3 $^{-1-}$ mice had been backcrossed to C57BL/6N for at least 14 generations. $\mathrm{A} 2 \mathrm{O}^{\mathrm{fl}+}$ mice were generated from gene-targeted C57BL/6 ES cells (Genoway, Lyon, France) and crossed to the general cre deleter strain C57BL/6-Gt(ROSA)26Sor ${ }^{\mathrm{tm} 16}$ ${ }^{(\text {cre) }}$ Arte to give $A 2 \mathrm{O}^{+/-}$mice. Ripk $3^{t /+}$ mice were generated at Genentech (South San Francisco, CA, USA) using C57BL/6N C2 ES cells. All alleles were maintained on a C57BL/6 genetic background. The A20/Tnfaip3 deleted region (first coding exon) corresponds to genomic position (NCBI37/mm9 assembly): chr10: $18730921-18732542$ (reverse strand). The Ripk3 floxed region (exons 2 and 3) corresponds to genomic position chr14: 56406 566-56 407332 (reverse strand).

A20 genotyping primers 5' CGC ATG AAG GCT TGT AGG ATG, 5' GTG GCA AAC AAC TGT GAT TCT GAT, and 5' CTG GTG AGT TCG CCT TGG A amplified 188 base pair (bp) wild-type and 449 bp deleted DNA fragments. Ripk3 primers
} 
5' ACG ATG TCT TCT GTC AAG TTA TG, 5' CAG TTC TTC ACG GCT CAC, and 5' TCT GGT AAG GAG GGT CAC amplified 304 bp wild-type, 338 bp floxed, and 218 bp deleted DNA fragments.

The Genentech animal care and use committee approved all mouse protocols.

Pancreatitis. In Figures 1a and b, wild-type and Ripk $3^{-1-}$ male mice aged 10 weeks were injected intraperitoneally with cerulein ( $50 \mu \mathrm{g} / \mathrm{kg}$ body weight) every hour for $10 \mathrm{~h}$ as described. ${ }^{3}$ These males were the offspring of parents of the same genotype from Ripk $3^{+/-}$grandparents. Serum plus pancreas were analyzed at $24 \mathrm{~h}$ after the first injection. In Figures $1 \mathrm{c}$ and $\mathrm{d}$, female littermates aged 11-13 weeks were injected intraperitoneally with cerulein ( $50 \mu \mathrm{g} / \mathrm{kg}$ body weight) every hour for a total of seven injections. Analyses were performed at $1 \mathrm{~h}$ after the final injection. Amylase in the serum was measured on a Beckman Coulter AU 480 analyzer (Beckman Coulter Life Sciences, Indianapolis, IN, USA) using 2-chloro-4nitrophenyl- $\alpha$-D-maltotrioside as an amylase substrate.

DSS-induced colitis. Female mice aged 8-10 weeks received DSS in their drinking water for 5 days. Histology of the rectum, proximal colon, middle colon, and distal colon on day 8 was scored on a scale of $0-5$ (Figure 2a) or 0-4 (Figure 2b) where $0=$ normal and $4 / 5=$ severe inflammation and complete loss of surface and crypt epithelium. A total of histology score for each mouse was obtained by adding together the scores of each level of the colon. Ripk $1^{+/+}$and Ripk $1^{K D / K D}$ females were littermates. Ripk $3^{+/+}$and Ripk $3^{-/}$female mice were the offspring of parents of the same genotype from Ripk3 ${ }^{+/-}$grandparents.

LPS-induced sepsis. In Figure 2c, male mice were aged 8 weeks and given $20 \mathrm{mg} / \mathrm{kg}$ body weight of Escherichia coli LPS 0111:B4 (cat\# L3012, lot\# 086K4082; Sigma-Aldrich, St. Louis, MO, USA) by intraperitoneal injection. Ripk $^{+/+}$and Ripk ${ }^{-/-}$males were the offspring of parents of the same genotype from Ripk $3^{+/-}$grandparents. In Figure 2d, female littermates were aged 10 weeks and received $18 \mathrm{mg} / \mathrm{kg}$ body weight of LPS (cat\# L3012, lot\# 110M4054; SigmaAldrich).

Imiquimod-induced psoriasis. Female littermates aged 8-10 weeks received $50 \mathrm{mg}$ of $5 \%$ imiquimod cream ( $3 \mathrm{M}$, St Paul, MN, USA) topically to the shaved back and right ear daily for 5 days. Clinical psoriasis scores between 0 and 5 $(0=$ no disease; $5=$ severe erythema with marked thickening and scaling involving $>50 \%$ of the treated area) and ear thickness were determined daily.

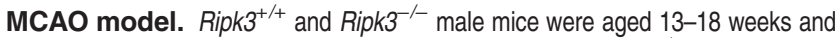
were the offspring of parents of the same genotype from Ripk $3^{+/}$grandparents. Mice were analyzed by MRA and surgery was the following day. Under anesthesia, the external carotid artery was tied off and the left common carotid artery was isolated with two sutures threaded under the artery. The distal suture that was closer to the heart was tied off. While holding the proximal suture taut to stop flow coming from the internal carotid, the common carotid artery was nicked and a 6-0 or 8-0 silicone coated nylon suture was introduced and advanced 7-9 $\mathrm{mm}$ beyond the carotid bifurcation. The incision was then closed. The occluder was kept in the mouse for a total of 50-60 min. Buprenorphine $(0.01-0.05 \mathrm{mg} / \mathrm{kg}$ body weight) was given subcutaneously while the occluder was in place and MRA was performed to verify complete occlusion. The mice were allowed to recover after imaging. At 30-40 min after imaging was completed (50-60 min after the occluder was placed), the animals were re-anesthetized and the occluder removed. The nicked artery was tied off and the incision closed. Mice received $0.5 \mathrm{ml}$ sterile saline or Ringer's lactate solution subcutaneously and were allowed to recover. Mice were imaged by T2-weighted MRI at $25 \mathrm{~h}$ post-surgery to determine the final brain infarct size. Mice were then killed and their brains stained with TTC. Animals were excluded from the analysis if they showed incomplete occlusion by MRA (nine wild-type mice and five Ripk3 ${ }^{-1}$ mice), if they exhibited hemorrhage from puncture of the artery during surgery (ome wild-type mouse and five Ripk $3^{-1-}$ mice), or if they had no PComAs by MRA (five wild-type mice and nine Ripk3-1- mice).

Hypoxia-induced cerebral edema. MRA was performed on Ripk $3^{+/+}$and Ripk3 $^{-/}$male mice aged 9-11 weeks. These mice were the offspring of parents of the same genotype from Ripk3 ${ }^{+-}$grandparents. The next day, the right cerebral artery was ligated under anesthesia. Mice were then placed in a hypoxic environment ( $8 \%$ oxygen, $92 \%$ nitrogen, $0.8 \%$ isoflurane) for 35 min between 0 and $3 \mathrm{~h}$ after surgery. Lidocaine was applied to the surgical site and then mice were allowed to recover. After $24 \mathrm{~h}$, the mice were killed and their brains stained with
TTC. Mice that died spontaneously prior to euthanasia (12 wild-type mice and 7 Ripk $3^{-/}$mice) were excluded along with animals that had no PComAs by MRA (9 wild-type mice and 16 Ripk $^{-/}$mice).

MRI. Animals were anesthetized using $3 \%$ isoflurane and placed in a custom-built head holder with ear bars and a tooth bar. During imaging, anesthesia was maintained using $1.5-2 \%$ isoflurane, keeping the respiration rate at $60-80$ breathsper-minute. The rectal temperature was monitored and maintained at $36.5-37.5^{\circ} \mathrm{C}$ using a feedback system with warm air (SA Instruments, Stony Brook, NY, USA).

All experiments were performed on a 9.4T/210 mm horizontal imaging system (Agilent Technologies, Santa Clara, CA, USA). The pre-screening MRA was acquired using a $30-\mathrm{mm}$ inner-diameter quadrature volume coil (millipede design; Agilent Technologies) and a 3D axial gradient-echo acquisition with a field-of-view (FOV) of $20 \times 10 \times 10 \mathrm{~mm}^{3}$, slab thickness $10 \mathrm{~mm}$, matrix size $128 \times 128 \times 128$ (zero-filled to $256 \times 256 \times 256$ ), repetition time (TR) $50 \mathrm{~ms}$, echo time (TE) $3 \mathrm{~ms}$, and flip angle $60^{\circ}$, resulting in a total scan time of approximately $14 \mathrm{~min}$. Images were inspected visually for PComAs.

The intraocclusion MRA and the 25-h time point relaxation rate T2 were acquired using a 40- $\mathrm{mm}$ inner-diameter quadrature volume coil (millipede design; Agilent Technologies) and a home-built head holder to minimize motion. The MRA acquisition parameters were identical to the pre-screening MRA. T2-weighted images were acquired using a 2D axial multi-echo, multi-slice experiment with FOV of $20 \times 20 \mathrm{~mm}^{2}$, 16 slices of $0.8 \mathrm{~mm}$ thickness, matrix size $64 \times 64$ (zero-filled to $128 \times 128$ ), $\mathrm{TR}=3000 \mathrm{~ms}, \mathrm{TE}=10,20,30,40,50,60,70$, and $80 \mathrm{~ms}$, and four averages. For each image pixel, $\mathrm{T} 2$ was calculated from the equation:

$\mathrm{S}(\mathrm{TE})=\mathrm{S}(0) \exp \left(-\frac{\mathrm{TE}}{\mathrm{T} 2}\right)$

The lesion size was determined using a semiautomated thresholding technique.

Myocardial infarction model. The left coronary artery of Ripk3 $3^{+/+}$and Ripk3 ${ }^{-1}$ male mice aged 15-21 weeks was occluded under anesthesia for 60 min (Biotrofix, Inc., Waltham, MA, USA). Mice were given buprenorphine $(0.05 \mathrm{mg} / \mathrm{kg}$ body weight) subcutaneously after surgery and then allowed to recover. Mice were killed 3 days after reperfusion and their hearts stained with TTC.

Kidney ischemia-reperfusion model. The left and right renal pedicles of male littermates aged 9-11 weeks were clamped for 30 min under anesthesia. After wound closure, mice received $0.5 \mathrm{ml}$ sterile saline intraperitoneally, and were allowed to recover. Mice received buprenorphine $(0.01-0.05 \mathrm{mg} / \mathrm{kg}$ body weight) at the time of anesthesia and then twice daily for 3 days. Moribund mice were killed. Sham-operated mice had incisions in the skin and muscle layer but the renal pedicles were not clamped.

TNF-induced SIRS. Littermates of both sexes were dosed with murine TNF (R\&D Systems, Minneapolis, MN, USA) intravenously via the tail vein. Body temperature was determined every $2 \mathrm{~h}$ for the first $12 \mathrm{~h}$ via a lubricated digital rectal probe. Mice with a body temperature below $23.6^{\circ} \mathrm{C}$ or that were moribund were killed. Serum cytokines and chemokines were assayed in independent experiments. Mice were killed and then blood was collected by cardiac puncture. Serum was examined by Luminex assay.

Immunohistochemistry. Staining for RIPK3 was performed as described. ${ }^{10}$

Western blots. BMDMs were lysed in $50 \mathrm{mM}$ Tris- $\mathrm{HCl} \mathrm{pH} 7.4,150 \mathrm{mM} \mathrm{NaCl}$, $2 \mathrm{mM}$ EDTA, 1\% NP-40, 0.1\% SDS, and $1 \mathrm{mM}$ DTT supplemented with protease and phosphatase inhibitors. Antibodies detected A20 (Cell Signaling Technology, Danvers, MA, USA, 5630S) or $\beta$-actin (Cell Signaling Technology, 5125S).

\section{Conflict of Interest}

All authors were employees of Genentech.

Acknowledgements. We thank Warren Alexander (WEHI, Australia) for $M / \mathrm{kH}^{-1}$ mice, Vishva M Dixit for scientific discussions, Deborah Siler for genotyping assay development, Jerome Anunciacion, Martin Garcia, Alexandra Verducci, Raymond Asuncion, Michael Long, Christopher Dela Cruz, and Elizabeth Magee for 
animal husbandry, and Robert J Newman, Søren Warming, Margaret Solon, Angela Martzell, Laurie Leong, and the histology laboratory for technical assistance.

1. Zhang DW, Shao J, Lin J, Zhang N, Lu BJ, Lin SC et al. RIP3, an energy metabolism regulator that switches TNF-induced cell death from apoptosis to necrosis. Science 2009; 325: 332-336.

2. Cho YS, Challa S, Moquin D, Genga R, Ray TD, Guildford M et al. Phosphorylation-driven assembly of the RIP1-RIP3 complex regulates programmed necrosis and virus-induced inflammation. Cell 2009; 137: 1112-1123.

3. He S, Wang L, Miao L, Wang T, Du F, Zhao L et al. Receptor interacting protein kinase-3 determines cellular necrotic response to TNF-alpha. Cell 2009; 137: 1100-1111.

4. Sun L, Wang H, Wang Z, He S, Chen S, Liao D et al. Mixed lineage kinase domain-like protein mediates necrosis signaling downstream of RIP3 kinase. Cell 2012; 148: 213-227.

5. Murphy JM, Czabotar PE, Hildebrand JM, Lucet IS, Zhang JG, Alvarez-Diaz S et al. The pseudokinase MLKL mediates necroptosis via a molecular switch mechanism. Immunity 2013; 39: 443-453.

6. Zhao J, Jitkaew S, Cai Z, Choksi S, Li Q, Luo J et al. Mixed lineage kinase domain-like is a key receptor interacting protein 3 downstream component of TNF-induced necrosis. Proc Natl Acad Sci USA 2012; 109: 5322-5327.

7. He S, Liang $Y$, Shao $F$, Wang $X$. Toll-like receptors activate programmed necrosis in macrophages through a receptor-interacting kinase-3-mediated pathway. Proc Natl Acad Sci USA 2011; 108: 20054-20059.

8. Kaiser WJ, Sridharan H, Huang C, Mandal P, Upton JW, Gough PJ et al. Toll-like receptor 3mediated necrosis via TRIF, RIP3, and MLKL. J Biol Chem 2013; 288: 31268-31279.

9. Wu J, Huang Z, Ren J, Zhang Z, He P, Li Y et al. Mlkl knockout mice demonstrate the indispensable role of Mlkl in necroptosis. Cell Res 2013; 23: 994-1006.

10. Newton K, Dugger DL, Wickliffe KE, Kapoor N, de Almagro MC, Vucic D et al. Activity of protein kinase RIPK3 determines whether cells die by necroptosis or apoptosis. Science 2014; 343: 1357-1360

11. Chen W, Zhou Z, Li L, Zhong CQ, Zheng X, Wu X et al. Diverse sequence determinants control human and mouse receptor interacting protein 3 (RIP3) and mixed lineage kinase domain-like (MLKL) interaction in necroptotic signaling. J Biol Chem 2013; 288: 16247-16261.

12. Wang H, Sun L, Su L, Rizo J, Liu L, Wang LF et al. Mixed lineage kinase domain-like protein MLKL causes necrotic membrane disruption upon phosphorylation by RIP3. Mol Cell 2014; 54: 133-146.

13. Su L, Quade B, Wang H, Sun L, Wang X, Rizo J. A plug release mechanism for membrane permeation by MLKL. Structure 2014; 22: 1489-1500.

14. Cai Z, Jitkaew S, Zhao J, Chiang HC, Choksi S, Liu J et al. Plasma membrane translocation of trimerized MLKL protein is required for TNF-induced necroptosis. Nat Cell Biol 2014; 16: $55-65$.

15. Dondelinger Y, Declercq W, Montessuit S, Roelandt R, Goncalves A, Bruggeman I et al. MLKL compromises plasma membrane integrity by binding to phosphatidylinositol phosphates. Cell Rep 2014; 7: 971-981

16. Hildebrand JM, Tanzer MC, Lucet IS, Young SN, Spall SK, Sharma P et al. Activation of the pseudokinase MLKL unleashes the four-helix bundle domain to induce membrane localization and necroptotic cell death. Proc Natl Acad Sci USA 2014; 111: 15072-15077.

17. Chen X, Li W, Ren J, Huang D, He WT, Song Y et al. Translocation of mixed lineage kinase domain-like protein to plasma membrane leads to necrotic cell death. Cell Res 2014; 24 : 105-121.

18. Rickard JA, O'Donnell JA, Evans JM, Lalaoui N, Poh AR, Rogers T et al. RIPK1 regulates RIPK3-MLKL-driven systemic inflammation and emergency hematopoiesis. Cell 2014; 157 : $1175-1188$.

19. Dannappel M, Vlantis K, Kumari S, Polykratis A, Kim C, Wachsmuth L et al. RIPK1 maintains epithelial homeostasis by inhibiting apoptosis and necroptosis. Nature 2014; 513: 90-94.

20. Rickard JA, Anderton H, Etemadi N, Nachbur U, Darding M, Peltzer $\mathrm{N}$ et al. TNFR1-dependent cell death drives inflammation in Sharpin-deficient mice. eLife 2014; 3: e03464.

21. Rodriguez DA, Weinlich R, Brown S, Guy C, Fitzgerald P, Dillon CP et al. Characterization of RIPK3-mediated phosphorylation of the activation loop of MLKL during necroptosis. Cell Death Differ 2016; 23: 76-88.

22. Lin J, Li H, Yang M, Ren J, Huang Z, Han F et al. A role of RIP3-mediated macrophage necrosis in atherosclerosis development. Cell Rep 2013; 3: 200-210.

23. Murakami $Y$, Matsumoto H, Roh M, Suzuki J, Hisatomi T, Ikeda Y et al. Receptor interacting protein kinase mediates necrotic cone but not rod cell death in a mouse model of inherited degeneration. Proc Natl Acad Sci USA 2012; 109: 14598-14603.

24. Linkermann A, Brasen JH, Darding M, Jin MK, Sanz AB, Heller JO et al. Two independent pathways of regulated necrosis mediate ischemia-reperfusion injury. Proc Natl Acad Sci USA 2013; 110: 12024-12029.

25. Vitner EB, Salomon R, Farfel-Becker T, Meshcheriakova A, Ali M, Klein AD et al. RIPK3 as a potential therapeutic target for Gaucher's disease. Nat Med 2014; 20: 204-208.

26. Luedde M, Lutz M, Carter N, Sosna J, Jacoby C, Vucur M et al. RIP3, a kinase promoting necroptotic cell death, mediates adverse remodelling after myocardial infarction. Cardiovasc Res 2014; 103: 206-216.
27. Zhang $T$, Zhang $Y$, Cui M, Jin L, Wang Y, Lv F et al. CaMKII is a RIP3 substrate mediating ischemia- and oxidative stress-induced myocardial necroptosis. Nat Med 2016; 22: 175-182.

28. Duprez L, Takahashi N, Van Hauwermeiren F, Vandendriessche B, Goossens V, Vanden Berghe T et al. RIP kinase-dependent necrosis drives lethal systemic inflammatory response syndrome. Immunity 2011; 35: 908-918.

29. Wong WW, Vince JE, Lalaoui N, Lawlor KE, Chau D, Bankovacki A et al. ClAPs and XIAP regulate myelopoiesis through cytokine production in an RIPK1- and RIPK3dependent manner. Blood 2014; 123: 2562-2572.

30. Lawlor KE, Khan N, Mildenhall A, Gerlic M, Croker BA, D'Cruz AA et al. RIPK3 promotes cell death and NLRP3 inflammasome activation in the absence of MLKL. Nat Commun 2015; 6 : 6282.

31. Moriwaki K, Bertin J, Gough PJ, Chan FK. A RIPK3-caspase 8 complex mediates atypical pro-IL-1beta processing. J Immunol 2015; 194: 1938-1944.

32. Newton $\mathrm{K}$, Sun X, Dixit VM. Kinase RIP3 is dispensable for normal NF-kappa B signaling by the B-cell and T-cell receptors, tumor necrosis factor receptor 1, and Toll-like receptors 2 and 4. Mol Cell Biol 2004; 24: 1464-1469.

33. Angele MK, Pratschke S, Hubbard WJ, Chaudry $\mathbb{H}$. Gender differences in sepsis: cardiovascular and immunological aspects. Virulence 2014; 5: 12-19.

34. Degterev A, Huang Z, Boyce M, Li Y, Jagtap P, Mizushima N et al. Chemical inhibitor of nonapoptotic cell death with therapeutic potential for ischemic brain injury. Nat Chem Biol 2005; 1: 112-119.

35. Schomer DF, Marks MP, Steinberg GK, Johnstone IM, Boothroyd DB, Ross MR et al. The anatomy of the posterior communicating artery as a risk factor for ischemic cerebral infarction. N Engl J Med 1994; 330: 1565-1570.

36. Varfolomeev EE, Schuchmann M, Luria V, Chiannilkulchai N, Beckmann JS, Mett IL et al. Targeted disruption of the mouse Caspase 8 gene ablates cell death induction by the TNF receptors, Fas/Apo1, and DR3 and is lethal prenatally. Immunity 1998; 9 : 267-276.

37. Lee EG, Boone DL, Chai S, Libby SL, Chien M, Lodolce JP et al. Failure to regulate TNF-induced NF-kappaB and cell death responses in A20-deficient mice. Science 2000; 289: $2350-2354$

38. Onizawa M, Oshima S, Schulze-Topphoff U, Oses-Prieto JA, Lu T, Tavares R et al. The ubiquitin-modifying enzyme A20 restricts ubiquitination of the kinase RIPK3 and protects cells from necroptosis. Nat Immunol 2015; 16: 618-627.

39. Van Hauwermeiren F, Armaka M, Karagianni N, Kranidioti K, Vandenbroucke RE, Loges S et al. Safe TNF-based antitumor therapy following p55TNFR reduction in intestinal epithelium. J Clin Invest 2013; 123: 2590-2603.

40. Mandal P, Berger SB, Pillay S, Moriwaki K, Huang C, Guo H et al. RIP3 induces apoptosis independent of pronecrotic kinase activity. Mol Cell 2014; 56: 481-495.

41. Holler N, Zaru R, Micheau O, Thome M, Attinger A, Valitutti S et al. Fas triggers an alternative, caspase-8-independent cell death pathway using the kinase RIP as effector molecule. Nat Immunol 2000; 1: 489-495.

42. Chan FK, Shisler J, Bixby JG, Felices M, Zheng L, Appel M et al. A role for tumor necrosis factor receptor-2 and receptor-interacting protein in programmed necrosis and antiviral responses. J Biol Chem 2003; 278: 51613-51621.

43. Polykratis A, Hermance N, Zelic M, Roderick J, Kim C, Van TM et al. Cutting edge: RIPK Kinase inactive mice are viable and protected from TNF-induced necroptosis in vivo. $\mathrm{J}$ Immunol 2014; 193: 1539-1543.

44. Berger SB, Kasparcova V, Hoffman S, Swift B, Dare L, Schaeffer M et al. Cutting edge: RIP1 kinase activity is dispensable for normal development but is a key regulator of inflammation in SHARPIN-deficient mice. J Immunol 2014; 192: 5476-5480.

45. Kumari S, Redouane Y, Lopez-Mosqueda J, Shiraishi R, Romanowska M, Lutzmayer S et al. Sharpin prevents skin inflammation by inhibiting TNFR1-induced keratinocyte apoptosis. eLife 2014; 3: e03422.

46. Weng D, Marty-Roix R, Ganesan S, Proulx MK, Vladimer GI, Kaiser WJ et al. Caspase-8 and RIP kinases regulate bacteria-induced innate immune responses and cell death. Proc Nat Acad Sci USA 2014; 111: 7391-7396.

47. Philip NH, Dillon CP, Snyder AG, Fitzgerald P, Wynosky-Dolfi MA, Zwack EE et al. Caspase-8 mediates caspase- 1 processing and innate immune defense in response to bacterial blockade of NF-kappaB and MAPK signaling. Proc Natl Acad Sci USA 2014; 111: 7385-7390.

48. Wang L, Du F, Wang X. TNF-alpha induces two distinct caspase-8 activation pathways. Cell 2008; 133: 693-703.

49. Dondelinger Y, Aguileta MA, Goossens V, Dubuisson C, Grootjans S, Dejardin E et al. RIPK3 contributes to TNFR1-mediated RIPK1 kinase-dependent apoptosis in conditions of clAP1/2 depletion or TAK1 kinase inhibition. Cell Death Differ 2013; 20: 1381-1392.

50. Lu TT, Onizawa M, Hammer GE, Turer EE, Yin Q, Damko E et al. Dimerization and ubiquitin mediated recruitment of A20, a complex deubiquitinating enzyme. Immunity 2013; 38 896-905.

51. De A, Dainichi T, Rathinam CV, Ghosh S. The deubiquitinase activity of A20 is dispensable for NF-kappaB signaling. EMBO Rep 2014; 15: 775-783.

52. Wertz IE, Newton K, Seshasayee D, Kusam S, Lam C, Zhang J et al. Phosphorylation and linear ubiquitin direct A20 inhibition of inflammation. Nature 2015; 528: 370-375.

53. Draber P, Kupka S, Reichert M, Draberova H, Lafont E, de Miguel D et al. LUBAC-recruited CYLD and $A 20$ regulate gene activation and cell death by exerting opposing effects on linear ubiquitin in signaling complexes. Cell Rep 2015; 13: 2258-2272. 
54. Smith CC, Davidson SM, Lim SY, Simpkin JC, Hothersall JS, Yellon DM. Necrostatin: a potentially novel cardioprotective agent? Cardiovasc Drugs Ther 2007; 21: 227-233.

55. Koudstaal S, Oerlemans MI, Van der Spoel TI, Janssen AW, Hoefer IE, Doevendans PA et al. Necrostatin-1 alleviates reperfusion injury following acute myocardial infarction in pigs. Eur $J$ Clin Invest 2015; 45: 150-159.

56. Linkermann A, Brasen JH, Himmerkus N, Liu S, Huber TB, Kunzendorf $U$ et al. Rip1 (receptor-interacting protein kinase 1) mediates necroptosis and contributes to renal ischemia/reperfusion injury. Kidney Int 2012; 81: 751-761.

57. Moriwaki K, Balaji S, McQuade T, Malhotra N, Kang J, Chan FK. The necroptosis adaptor RIPK3 promotes injury-induced cytokine expression and tissue repair. Immunity 2014; 41: 567-578.

58. Liu ZY, Wu B, Guo YS, Zhou YH, Fu ZG, Xu BQ et al. Necrostatin-1 reduces intestinal inflammation and colitis-associated tumorigenesis in mice. Am J Cancer Res 2015; 5: 3174-3185.

59. Takahashi N, Duprez L, Grootjans S, Cauwels A, Nerinckx W, DuHadaway JB et al. Necrostatin-1 analogues: critical issues on the specificity, activity and in vivo use in experimental disease models. Cell Death Dis 2012; 3: e437.
60. Madison BB, Dunbar L, Qiao XT, Braunstein K, Braunstein E, Gumucio DL. Cis elements of the villin gene control expression in restricted domains of the vertical (crypt) and horizontal (duodenum, cecum) axes of the intestine. J Biol Chem 2002; 277: 33275-33283.

(c) (i) (3) $\odot$ This work is licensed under a Creative Commons Attribution-NonCommercial-NoDerivs 4.0 International License. The images or other third party material in this article are included in the article's Creative Commons license, unless indicated otherwise in the credit line; if the material is not included under the Creative Commons license, users will need to obtain permission from the license holder to reproduce the material. To view a copy of this license, visit http://creativecommons.org/licenses/by-nc-nd/4.0/

(C) The Author(s) 2016

Supplementary Information accompanies this paper on Cell Death and Differentiation website (http://www.nature.com/cdd) 